\title{
Correlation of body mass index and abnormal uterine bleeding in premenopausal women
}

\author{
Kumarasamy Akalyaa, Pattacheravanda Nanaiah Shakuntala*, Ramaiah Renuka
}

\begin{abstract}
Department of Obstetrics and Gynaecology, ESIC Medical College and Post Graduate Institute of Medical Science and Research, Rajaji Nagar, Bangalore, Karnataka, India
\end{abstract}

Received: 05 October 2020

Revised: 16 October 2020

Accepted: 19 October 2020

\author{
*Correspondence: \\ Dr. Pattacheravanda Nanaiah Shakuntala, \\ E-mail: shakuntala_pn@yahoo.com
}

Copyright: (c) the author(s), publisher and licensee Medip Academy. This is an open-access article distributed under the terms of the Creative Commons Attribution Non-Commercial License, which permits unrestricted non-commercial use, distribution, and reproduction in any medium, provided the original work is properly cited.

\section{ABSTRACT}

Background: As the rate of obesity is increasing in women in the recent years, the incidence of endometrial cancer increases as the body mass index (BMI) increases. Despite the clear evidence linking endometrial cancer and obesity, there is limited public awareness of this relationship. This study was undertaken to evaluate the association of BMI and endometrial pathology in premenopausal women with abnormal uterine bleeding (AUB).

Methods: An analytical case control study was conducted in 100 women between the age group of 40 to 55, with AUB in the Department of Obstetrics and Gynecology, ESIC-PGIMSR Bangalore between January 2018 and June 2019. The menstrual patterns and endometrial pattern by histopathology were analysed in women with BMI of 18.5 to 24.99 and $\geq 25$.

Results: The mean age of women participated in the study group of between 40- 55 years was 44.83. The mean duration of symptoms was 10.18 months in the cases group and 8.52 months in the control group. The menstrual patterns were comparable and there was no significant difference in both the groups. The mean endometrial thickness, mean BMI, hyperplasia with or without atypia were all higher in the cases group. The frequency of occurrence of atypical endometrial hyperplasia was higher in women with increasing BMI.

Conclusions: We found increased BMI to be an important independent risk factor for the development of endometrial hyperplasia with atypia which is a precursor to endometrial carcinoma in premenopausal women with AUB.

Keywords: Abnormal uterine bleeding, Endometrial hyperplasia, Endometrial thickness, Body mass index

\section{INTRODUCTION}

According to International Federation of Gynecology and Obstetrics (FIGO) abnormal uterine bleeding (AUB) is defined as bleeding from the uterine corpus that is abnormal in volume, regularity, frequency or duration and occurs in the absence of pregnancy. AUB is a common complaint encountered in Gynaecology outpatient department (OPD). It occurs in 9 to $14 \%$ of women from menarche to menopause affecting quality of life imposing financial burden. ${ }^{1}$
Recent global statistics showed that $35 \%$ of the adult population (age 20+) is overweight (body mass index $\geq 25$ $\mathrm{kg} / \mathrm{m}^{2}$ ) and $12 \%$ obese (body mass index $\geq 30 \mathrm{~kg} / \mathrm{m}^{2}$ ). While the current prevalence of excess body mass index (BMI) is around $10 \%$ in many Asian and African countries. $^{2}$

Over the past 2 decades there has been global recognition of increasing levels of obesity. At the same time, there is epidemiological evidence of increased incidence of endometrial cancer. Several systematic reviews have shown an association between obesity and endometrial cancer. However, given that the majority of endometrial 
cancer occurs in postmenopausal women, it has not been widely recognized that obesity is a significant risk factor for endometrial hyperplasia and cancer in young, symptomatic, premenopausal women. ${ }^{3}$

Recent meta-analyses suggest that women who are overweight or obese have a 1.43 or 3.33 fold increase in risk for developing endometrial cancer, compared to women with normal weight. ${ }^{4}$

Developing a greater understanding of the leading risk factors for premenopausal women would lead to improved clinical pathways from primary to secondary care and improved targeting of invasive diagnostic testing. Deciding to biopsy primarily based on age, as currently recommended in national guidelines, potentially misses many cases or delays diagnosis. Body mass index should be the first stratification in the decision to perform endometrial biopsy and/or to refer secondary gynaecology services.

The current study was aimed to evaluate the association of body mass index and endometrial pathology in premenopausal women with AUB.

\section{METHODS}

Our study was analytical, case control study conducted on 100 women after obtaining institutional ethical committee approval with AUB who attended the Department of Obstetrics and Gynaecology, ESIC-PGIMSR Bengaluru between January 2018 and June 2019 (18 months), with the sample size of 100 cases. These women were subjected for height and weight measurement, calculation of BMI, and detailed history, examination, and baseline investigations including complete hemogram, LFT, renal function tests (RFT), coagulation profile and pelvic ultrasound followed by endometrial biopsy and the histopathological report was studied for the endometrial pattern. The diagnostic intervention was done with endometrial sampling by D and C or Pipelle for both groups.

BMI was calculated by:

$$
\begin{aligned}
& \text { Quetelet index }- \text { weight in } \mathrm{kgs} \\
& \quad \div \text { height in meter square }
\end{aligned}
$$

\section{Sample size estimation}

The sample size for the present case control study was calculated by considering the odds ratio for developing the endometrial cancer in overweight premenopausal women to the normal weight as 3.5 from the previously published literature. This gave disease exposure rate to be $70 \%$ in overweight and $40 \%$ in normal weight groups. The minimum sample size had been calculated to be 42 cases in each group with $30 \%$ as effect size at $5 \%$ level of significance which gives at least $80 \%$ power assuming two tailed hypotheses. Therefore, the minimum total sample size of the study was set as 84 cases. But the study was conducted on 100 women. Following formula was used to calculate the sample size:

$$
\begin{aligned}
n=\left[Z_{\propto \div 2} \sqrt{2 \times P(1-P)}+Z_{\beta} \sqrt{P_{o}\left(1-P_{o}\right)}\right. \\
+{\sqrt{P_{1}\left(1-P_{1}\right)}}^{2} \div\left(P_{o}-P_{1}\right)^{\wedge} 2
\end{aligned}
$$

Where, $\mathrm{Z} \propto \div{ }_{2}=1.96, \mathrm{Z}_{\beta}=0.84, \mathrm{P}_{0}=0.40, \mathrm{P}_{1}=0.70$ and

$$
P=P_{o}-P_{1} \div 2
$$

\section{Inclusion criteria}

The inclusion criteria for the study was as follows: women who were willing to give written informed consent and all women attending Gynaecology OPD with complaint of AUB in the age group of 40 to 55 years with BMI of 18.5 to 24.99 and $\geq 25$.

\section{Exclusion criteria}

The exclusion criteria for the study was as follows: existing cervical, uterine and ovarian cancer; pelvic inflammatory disease; premenopausal women with coagulation disorders; on-going pregnancy; and women with thyroid disorders, liver disorders, chronic kidney disease.

Results were analysed as continuous (age, duration of symptoms and endometrial thickness) and categorical (parity, menstrual pattern and ultrasound (USG) and histopathological analysis) variables using independent $t$ test and chi square/Fischer exact text respectively. $\mathrm{P}$ value was considered significant if it is less than 0.05 .

\section{RESULTS}

The primary outcome of the study was the comparison of the menstrual pattern and the comparison of the histopathological report for the endometrial pattern of the women in both the groups. Mean age, duration of AUB, association of comorbidities were the secondary outcomes studied. Case- 50 women with BMI of $\geq 25$, control groupwomen with BMI of 18.5 to 24.99 .

\section{Age group and parity}

The mean age of women participated in the study group of between 40-55 years was 44.83 years while with the control group and cases group was 45.14 and 44.52 respectively. The $\mathrm{p}$ value was 0.3 which was not statistically significant, which rendered both the group comparable with respect to age. Maximum number of women were with parity 2, with $54 \%$ ( 27 women) and $48 \%$ ( 24 women) in control and cases group respectively. $\mathrm{P}$ value was 0.82 . The second-high number of women fall under parity 3 with 14 women $(28 \%)$ and 12 women $(24 \%)$ in control and case group respectively. 


\section{Duration of symptoms}

The duration of symptoms of AUB was compared in both the groups, with the mean duration in 100 women was 9.35 months. The mean duration of symptoms was 10.18 months in the cases group and 8.52 months in the control group, with the $\mathrm{p}$ value of 0.13

\section{Menstrual patterns}

The menstrual patterns were variedly studied in both the groups with respect to disturbance of frequency and regularity, disturbance of duration of flow, heaviness of flow. The menstrual patterns were comparable and there was no significant difference in both the groups. $61 \%$ of total women had regular menstrual bleeding and 39\% had irregular menstrual bleeding. P value was statistically not significant which was 0.84 .
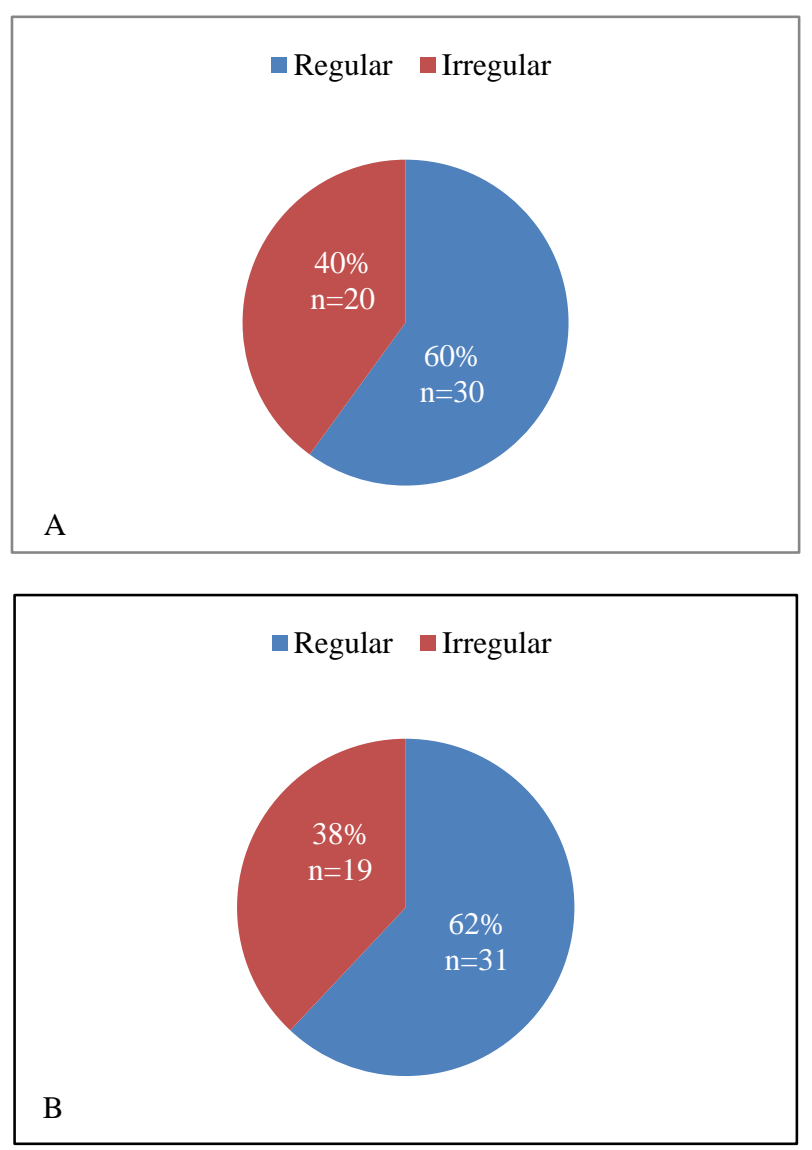

Figure 1: Comparison of disturbance in regularity of menstrual bleeding among both the groups,

(A) menstrual pattern control group, (B) menstrual pattern cases group.

Among 100 women studied $43 \%$ had normal frequency of cycle, $49 \%$ had frequent menstrual cycle and $8 \%$ had infrequent cycles. 0.70 was the $\mathrm{p}$ value which was statistically not significant.

The amount of menstrual flow was comparable with both the case and control group as normal menstrual bleeding and heavy menstrual bleeding. 33\% of women had normal and $67 \%$ of women heavy menstrual bleeding. P value was 0.83 which was statistically not significant.

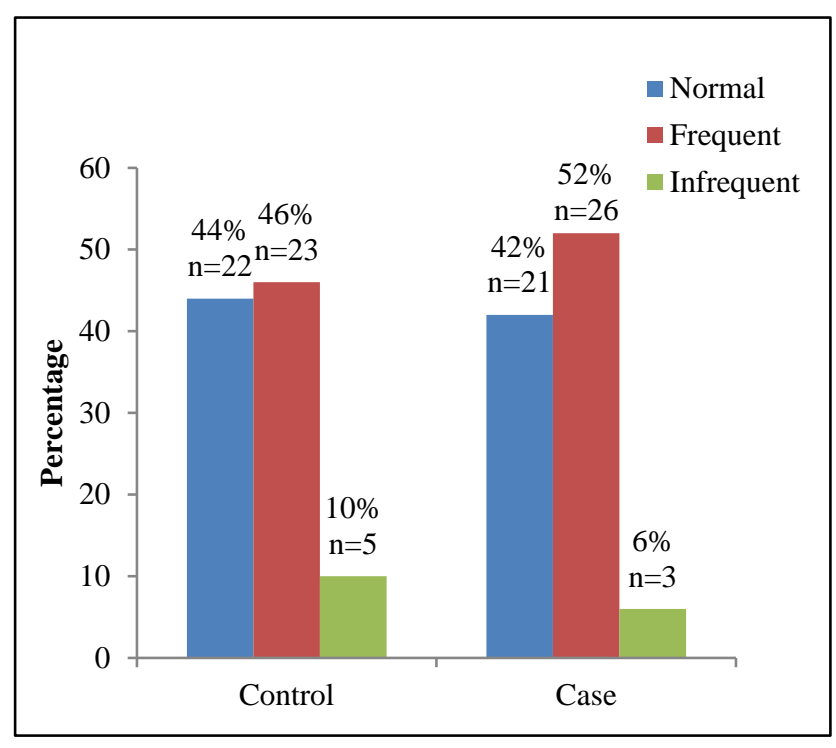

Figure 2: Comparison of frequency of menstrual cycle $(n=100)$.
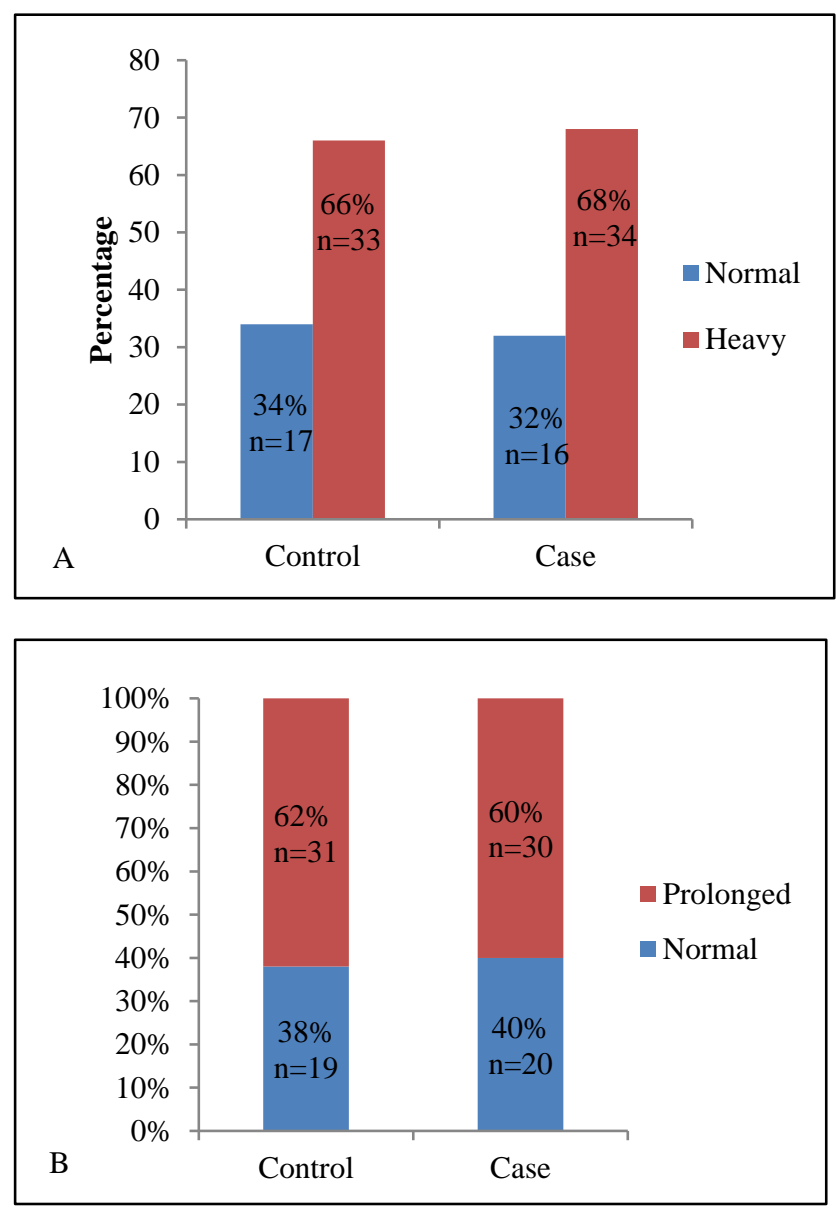

Figure 3: (A) Comparison of menstrual flow among both the groups, (B) comparison of menstrual duration among both the groups $(n=100)$. 
The duration of menstrual bleeding was compared in both the groups as normal menstrual bleeding and prolonged menstrual bleeding. Among 100 women in the study $39 \%$ had normal duration of flow and $61 \%$ had prolonged menstrual flow with the $\mathrm{p}$ value of 0.84 which was statistically not significant.

\section{Comparison of body mass index}

The mean BMI was compared in both the groups with the cases groups was 28.99 while the mean BMI in the control group was 22.1 .

A
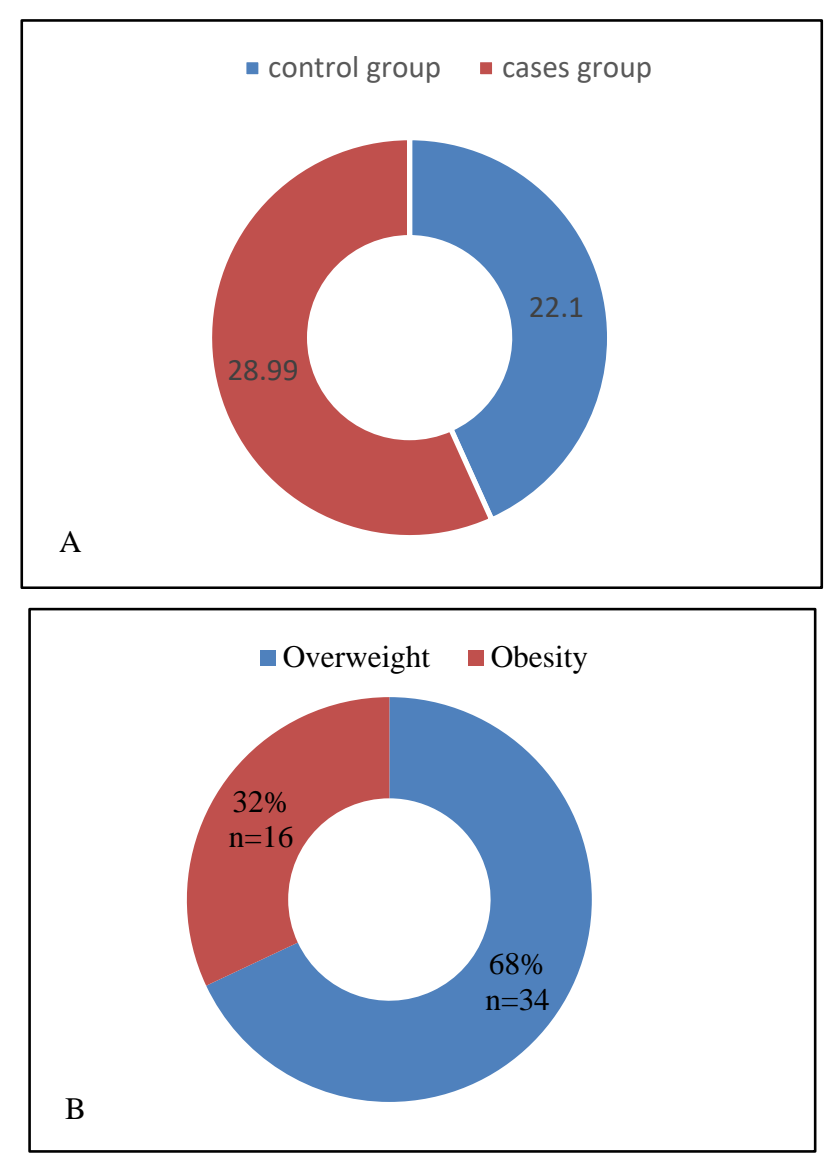

Figure 4: (A) Comparison of mean body mass index, (B) distribution of overweight and obesity.

The total number of women with overweight (BMI of 25 to 29.99$)$ was $34(68 \%)$ and the total number of women with obesity (BMI of $\geq 30)$ was $16(32 \%)$.

\section{Ultrasonographic findings}

All the women in the study group were subjected to ultrasound examination for uterine size, endometrial thickness and adnexa was looked for any pathology.

Among 100 women in both the groups, $68 \%$ (34) and 56\% (28) of women had normal uterine size, rest $32 \%$ (16) and $44 \%$ (22) of women had bulky uterus in control group and cases group respectively.
With the comparison of endometrial thickness in both the groups the mean endometrial thickness was $16.43 \mathrm{~mm}$. The minimal endometrial thickness studied was $8 \mathrm{~mm}$ seen in the control group and the maximum was $26 \mathrm{~mm}$ seen in the cases group. The mean endometrial thickness in control group and cases group was $15.8 \mathrm{~mm}$ and $17.06 \mathrm{~mm}$ respectively. The $\mathrm{p}$ value was 0.09 which was statistically not significant.

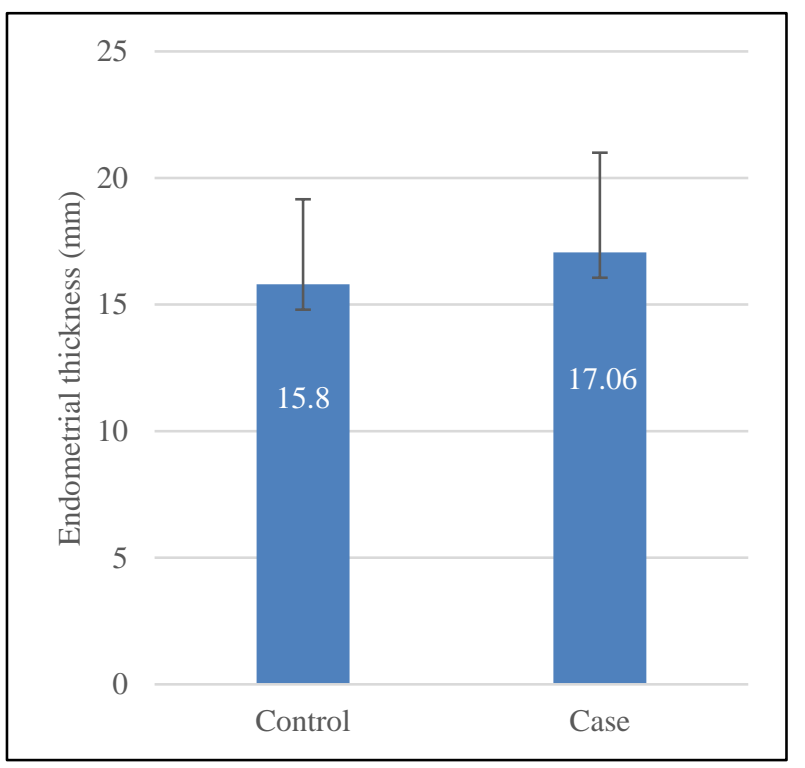

Figure 5: Comparison of endometrial thickness.

\section{Comorbidities}

With the comparison of comorbidities among both the groups, $60 \%$ (30 women) and 54\% (27 women) of women had no comorbidities associated with AUB. Diabetes mellitus type 2 was seen in 20\% (10 women) and 24\% (12 women) in control and cases group respectively. The presence of anaemia was equal in both the groups of $12 \%$ (6 women). Hypertension was seen in $8 \%$ (4 women) in control group and $10 \%$ (5 women) in cases group. $\mathrm{P}$ value being 0.93 which was statistically not significant.

\section{Histopathological correlation}

Among the histopathological findings in both the groups, normal histopathological findings were more common in the control group with secretory phase endometrium in $36 \%$ (18 women) followed by proliferative endometrium of $12 \%$ ( 6 cases) and biphasic endometrium in 1 woman $(2$ $\%)$. In the cases group the number of women with secretory and proliferative endometrium were $18 \%$ (9 cases) and 6\% (3 cases) respectively, and biphasic endometrium was $2 \%$ ( 1 case).

Other patterns including disordered proliferative endometrium was seen in both control and cases group of $6 \%$ (3 women) and 8\% (4 women) respectively. 


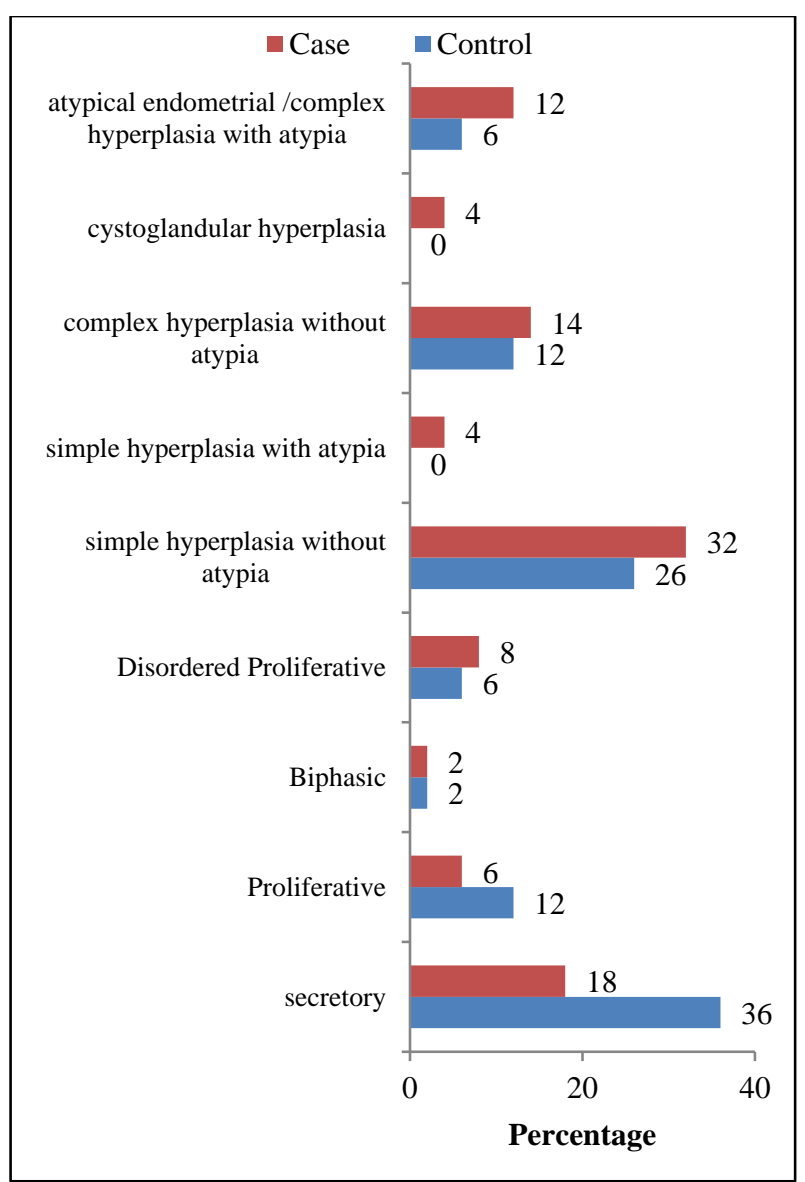

Figure 6: Comparison of histopathological findings $(\mathbf{n}=\mathbf{1 0 0})$.

Among the endometrial patterns, the percentage of hyperplasia (all types) diagnosed by endometrial biopsy was high in both the groups. Of 100 women in the present study 55 women had endometrial hyperplasia and 46 women had other patterns with the $\mathrm{p}$ value of 0.07 .

Simple hyperplasia without atypia was common with $26 \%$ and $32 \%$ respectively in control and cases group while simple hyperplasia with atypia was $4 \%$ in cases group and zero in control group.

Complex hyperplasia without atypia was seen in $12 \%$ (6 women) and 14\% (7 cases) in AUB with control group and cases group respectively. Complex hyperplasia with atypia was 6\% (3 women) and $12 \%$ (6 women) in control and cases respectively. Cysto-glandular hyperplasia was seen in 2 women (4\%) in the cases group.

With the comparison of endometrial hyperplasia from the histopathology report of all 100 women, the percentage of women having hyperplasia with or without atypia was more in women with BMI of $\geq 25$ (case group). $44 \%$ (22 women) and $66 \%$ (33 women) were diagnosed to have endometrial hyperplasia in both control and case group respectively. Though a greater number of hyperplasia was seen in the high BMI group, the p value of 0.07 was not statistically significant.
Out of 55 women with hyperplasia, 33 were in the cases group and 22 women in the control group. the mean endometrial thickness was $16.09 \mathrm{~mm}$ and $16.8 \mathrm{~mm}$ in the cases and control group respectively which was comparable, the mean BMI was 22.3 in the control group and 28.99 in the cases group respectively. $\mathrm{P}$ value of 0.5 which was statistically not significant.
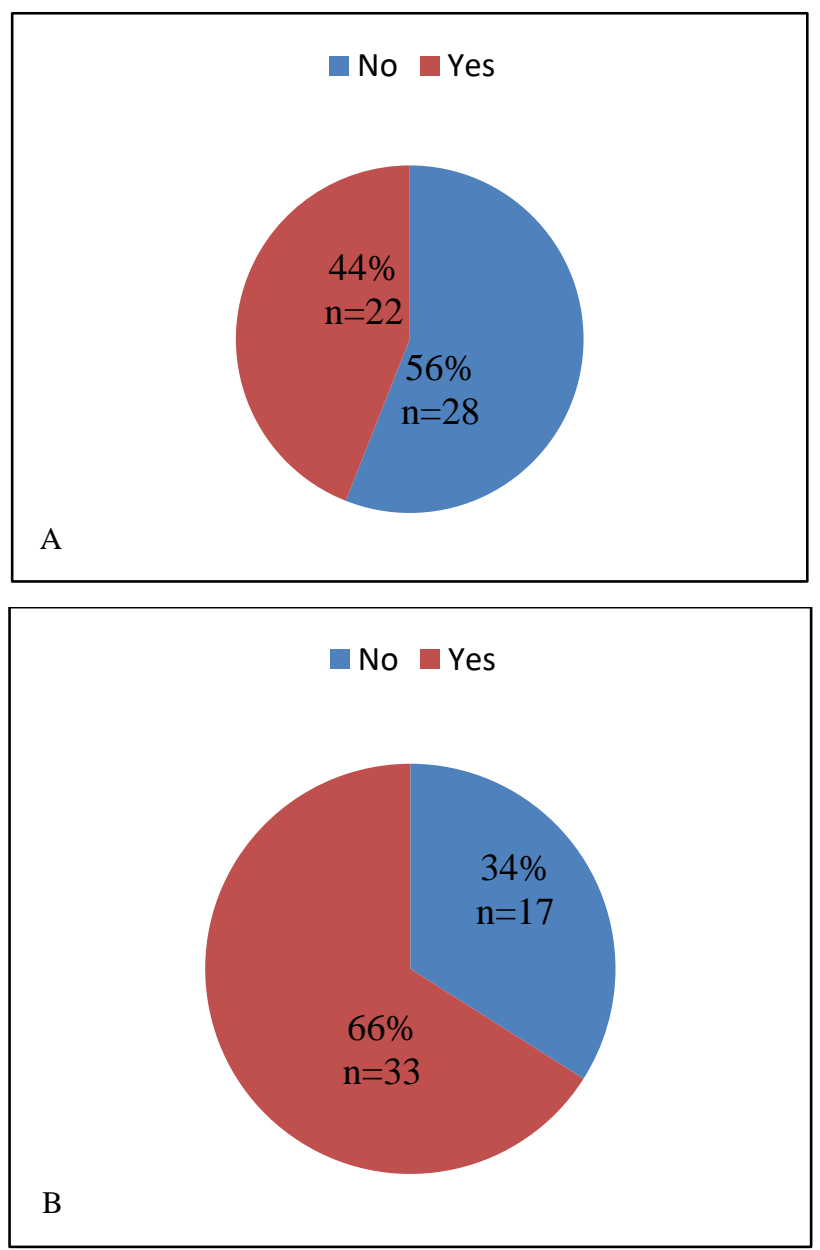

Figure 7A: Comparison of endometrial hyperplasia among the study groups (A) endometrial hyperplasia in control group), (B) endometrial hyperplasia in cases.

Among the 100 women in the present study group 11 women developed hyperplasia with atypia, 8 women from the cases group and 3 women from the control group. The mean endometrial thickness and the mean BMI were studied in these 11 women.

The mean BMI in both the groups was found to be 29.25 in the cases group and 22 in the control group, likewise the mean endometrial thickness was $16 \mathrm{~mm}$ and $18 \mathrm{~mm}$ in the cases and control group respectively. Among the 8 women in the cases group, 5 women were in the overweight category and 3 women in the obese category. 


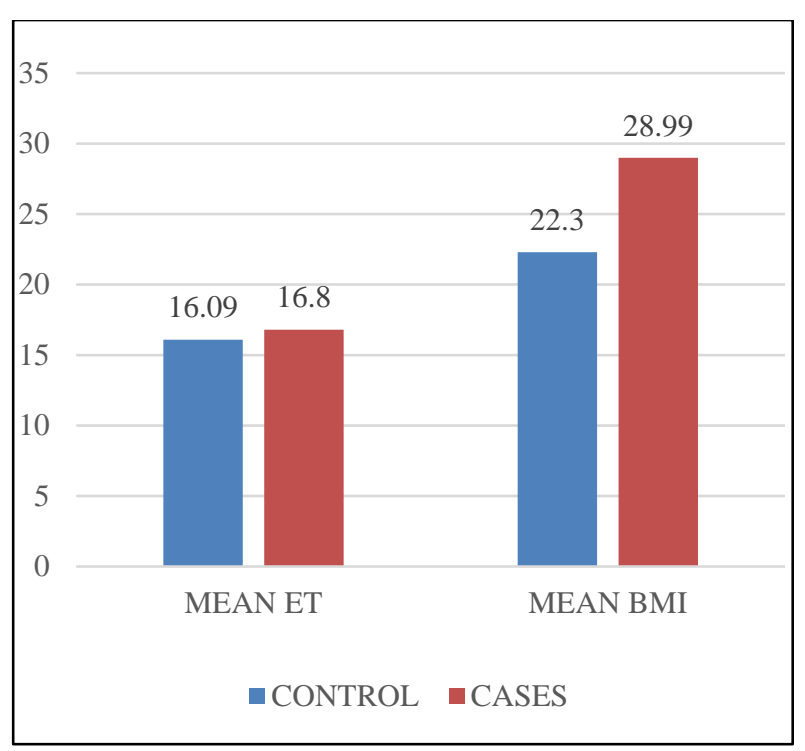

Figure 8: Comparison of mean endometrial thickness and body mass index.

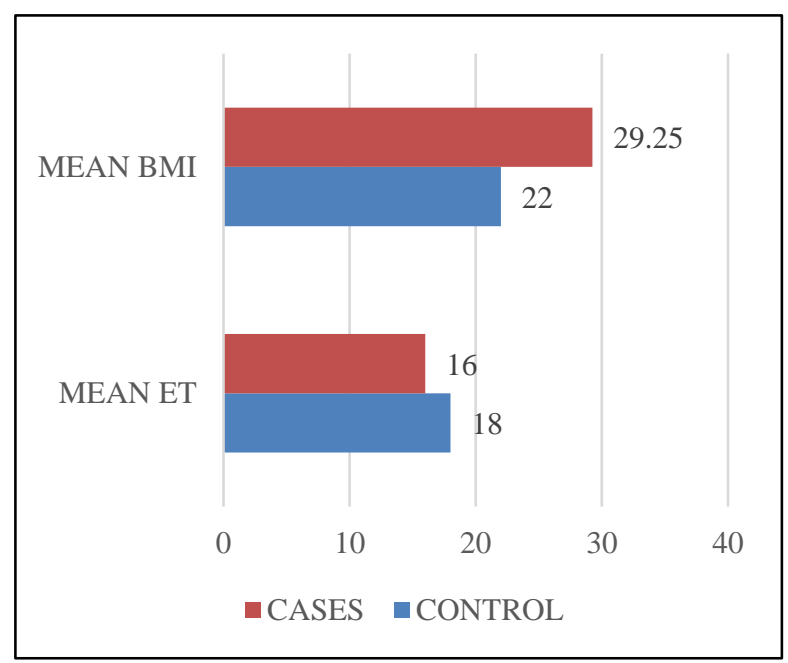

Figure 9: Comparison of mean endometrial thickness and mean body mass index among the study groups.

\section{DISCUSSION}

The primary outcome of the study was the comparison of the menstrual pattern and the comparison of the histopathological report of these women in both the groups. Mean age, duration of AUB, associated comorbidities were also studied.

The demographic characteristics of both the groups were found to be comparable, in terms of age with the mean age of women with the normal BMI and (control group) was 45.14 and in the cases group was 44.52 years. The mean duration of symptoms in control group was 8.52 months and in the cases group was 10.18 months.

In our study the most common endometrial pattern was secretory and proliferative endometrium which was $36 \%$.
The endometrial biopsy compared by Wise et al3 in 2016, the most common endometrial pattern seen in the biopsy was the normal endometrium like secretory and proliferative phase seen in $41.1 \%$ followed by disordered proliferative endometrium which was $20.5 \%$. The incidence of endometrial cancer or hyperplasia with atypia was $4.9 \%$ in women with AUB with the BMI of more than 30 which was comparable with our study with the presence of endometrial hyperplasia with atypia seen in $8 \%$ of women with BMI of $\geq 25$ and $3 \%$ in women with BMI $<25$. In the present study obese women had more atypia along with hyperplasia in the endometrial patterns compared to the women with normal BMI.

The menstrual patterns were variedly studied in both the groups with respect to disturbance of frequency and regularity, disturbance of duration of flow, heaviness of flow.

The different menstrual irregularities did not significantly affect the outcome. Menstrual history had no effect on the endometrium according to Wise et al, 2016 which was comparable with our study, where the menstrual irregularities were similar in both the groups. ${ }^{3}$

Seif et al in 2015 reported that the prevalence of menstrual cycle irregularities was $8.4 \%$ in women who were $74 \%$ overweight, as compared to $2.6 \%$ in women who were $<20 \%$ overweight. ${ }^{5} \mathrm{~A}$ further study documented that being $15 \%$ overweight was associated with a significantly higher chance of having a menstrual cycle longer than 43 days.

In the present study $52 \%$ of women in the cases group had frequent cycles, $68 \%$ had heavy menstrual bleeding, $30 \%$ had prolonged menstrual bleeding and 38\% had regular cycle length in comparison with the control group where $60 \%$ had regular cycles, $46 \%$ had frequent cycles, $66 \%$ had heavy menstrual bleeding and $31 \%$ had prolonged menstrual bleeding which was consistent with the previous studies.

In the study conducted by Wise et al, the mean duration of AUB in the control group was 3.4 years while the mean duration of AUB in the cases group was 3.8 years, which was comparable with the present study with the mean duration of AUB in the control group and the cases groups were 8.52 months and 10.18 months respectively. ${ }^{3}$

Comparison of endometrial thickness with respect to AUB was made by Wise et al, where the mean endometrial thickness in the control group and the cases group were $16.5 \mathrm{~mm}$ and $26 \mathrm{~mm}$ respectively which was comparable with the present study with the endometrial thickness of $15.8 \mathrm{~mm}$ and $17.06 \mathrm{~mm}$ in the control group and the cases group respectively. ${ }^{3}$

Nouri et al studied the pathological effects of obesity on triggering DUB, they suggested that thickened endometrium and uterine wall hyperplasia can predispose to AUB. ${ }^{6}$ 
In the present study the endometrial thickness in the cases group was 17.06 which was higher than control group (15.8) and the uterine size comparison was consistent with the study conducted by Nouri et al, where $44 \%$ in the cases group and $32 \%$ in the control group had bulky uterus. ${ }^{6}$

In the cases group the mean BMI of women were studied for its correlation with AUB, according to Nouri et al, 2014 the mean BMI of women in the study group was 32.63 while the mean BMI according to Sharma et al, 2018 was 27.92 which was comparable with the present study where the BMI was 28.99 indicating the higher incidence of AUB in obese and overweight women. ${ }^{6,8}$ According to Farquhar et al, 1999 they concluded that obesity and BMI were independent risk factors contributing to endometrial hyperplasia and endometrial cancer. ${ }^{7}$

Table 1: comparison between overweight and obesity.

\begin{tabular}{|c|c|c|}
\hline $\begin{array}{l}\text { Study } \\
\text { conducted by }\end{array}$ & $\begin{array}{l}\text { Overweight } \\
(25-29.99)\end{array}$ & $\begin{array}{l}\text { Obese } \\
(>30)\end{array}$ \\
\hline Sharma et al ${ }^{8}$ & $56.25 \%$ & $25 \%$ \\
\hline Present study & $34(68 \%)$ & $16(32 \%)$ \\
\hline
\end{tabular}

Sharma et al, in 2016, concluded that almost $81 \%$ of cases had abnormal BMI. More than half of cases in the study group $(56.25 \%)$ were overweight and $8 \%$ that was onefourth women were obese. ${ }^{8}$

Nouri et al concluded that two-third of studied women suffered from overweight status and other one third cases were obese. ${ }^{6}$ In the present study (34 cases) $68 \%$ of women were overweight and $36 \%$ of women (18 cases) were obese according to World Health Organization (WHO) BMI classification which was consistent with the above two results.

Though the present study may be limited with smaller sample size, the relation of BMI with AUB and existence of longer duration of symptoms of AUB in overweight and obese women was well correlated.

The risk factors were comparable and the number of women having diabetes and hypertension were equal in both the groups. Wise et al, concluded that there was no association between diabetes and hypertension as a risk factor for the development of endometrial hyperplasia. ${ }^{3}$

Endometrial thickness of more than $12 \mathrm{~mm}$ was considered to be thickened endometrium in premenopausal women with AUB. In the present study the number of women with endometrial thickness of more than $12 \mathrm{~mm}$ were 92 out of 100 women which was comparable with the study conducted by Wise et al, 2016 where they concluded that women with endometrium thickness of $12 \mathrm{~mm}$ had significantly higher odds of having complex hyperplasia or cancer. $^{3}$

In the present study, the mean endometrial thickness in women who developed endometrial hyperplasia with atypia was $16 \mathrm{~mm}$ and $18 \mathrm{~mm}$ in cases and control group respectively which was found to highly associated with the development of endometrial hyperplasia as compared with the previous studies.

Likewise, the mean BMI between the women with hyperplasia with atypia was studied and was found to be $29.25 \mathrm{~kg} / \mathrm{m}^{2}$ in the cases group which was comparable with the study by Wise et al, 2016 where they had a significant association between high BMI and development of endometrial hyperplasia with atypia which was considered to be a precursor to endometrial carcinoma. ${ }^{3}$ Obese women had significantly higher odds of having complex hyperplasia or cancer compared to women with normal BMI (adjusted OR, 4.00; 95\% Confidence interval (CI), 1.36-11.74),

Renehan et al, 2008 in their study found that for every increase in BMI of $5 \mathrm{~kg} / \mathrm{m}^{2}$ which significantly increased a woman's risk of the development of endometrial cancer (relative risk (RR), 1.59; 95\% CI, 1.50-1.68). ${ }^{9}$ Therefore, we summarize that premenopausal women with a BMI of $>25 \mathrm{~kg} / \mathrm{m}^{2}$ have an increased risk for developing higher grades of hyperplasia of the endometrium than compared to the premenopausal women with the same degree of endometrial thickness cut off of $12 \mathrm{~mm}$.

\section{Limitations of the study}

Statistical significance could not be attained due to limited number of study group. Disease onset to endpoint cannot be commented as it is dependent on the onset of obesity and the menstrual abnormalities to presentation of symptoms. The cut off for different grades of BMI is narrow hence the outcome varies depending on the duration of exposure to different grades of BMI.

\section{CONCLUSION}

Obesity is considered to be an epidemic globally. In the present study we found that increased BMI to be an important independent risk factor for the development of endometrial hyperplasia with atypia which is a precursor to endometrial carcinoma in premenopausal women with AUB. Although age, duration of symptoms and duration of menopause were considered as an important parameter for the evaluation of the endometrium in premenopausal and post-menopausal women, this led to delay in the detection of endometrial carcinoma in these women. Therefore, body mass index should be set as the first criteria for premenopausal women to undergo evaluation of the endometrium for early detection and prevention of endometrial hyperplasia or carcinoma. The association of obesity with endometrial cancer, breast cancer and colonic cancer have been emphasised in the literature. Need for public awareness on the ill effects of cancer which can be prevented by maintaining a normal BMI need to be publicized. 


\section{ACKNOWLEDGMENTS}

We thank our beloved Dean, academic registrar, scientific and ethical committee members for their input.

Funding: No funding sources

Conflict of interest: None declared

Ethical approval: The study was approved by the Institutional Ethics Committee

\section{REFERENCES}

1. Munro MG, Critchley HO, Fraser IS. FIGO classification of causes of AUB. Int $\mathrm{J}$ Gynaecol Obstet. 2011;113:3-13.

2. Arnold M, Pandeya N, Byrnes G, Renehan PAG, Stevens GA, Ezzati PM, et al. Global burden of cancer attributable to high body-mass index in 2012: a population-based study. The Lancet Oncology. 2015;16(1):36-46.

3. Wise MR, Gill P, Lensen S, John, Thompson, Farquhar CMl. Body mass index trumps age in decision for endometrial biopsy: cohort study of symptomatic premenopausal women. Am J Obstet Gynecol. 2016;215:598.e1-8.

4. Gao Y, Dai X, Chen L, Lee AC, Tong M, Wise M et al. Body Mass Index Is Positively Associated with
Endometrial Cancer in Chinese Women,Especially Prior to Menopause. J Cancer. 2016;7:1169-73.

5. Seif MW, Diamond K, Nickkho-Amiry M. Obesity and menstrual disorders. Best Pract Res Clin Obstet Gynaecol. 2015;29:516-27.

6. Nouri M, Tavakkolian A, Mousavi SR. Association of dysfunctional uterine bleeding with high body mass index and obesity as a main predisposing factor. Diab Metabol Synd Clin Res Rev. 2014;8:1-22.

7. Farquhar CM, Lethaby A, Sowter M, Verry J, BHB, Baranyai J. An evaluation of risk factors for endometrial hyperplasia in premenopausal women with abnormal menstrual bleeding. Am J Obstet Gynecol.1999;181:525-9.

8. Sharma AS, Gupta S. Analysis of body mass index in patients with AUB. Inter J Clin Obstet Gynaecol. 2019;3(1):92-5.

9. Renehan AG, Tyson M, Egger M, Heller RF, Zwahlen M. Body-mass index and incidence of cancer: a systematic review and meta-analysis of prospective observational studies. Lancet. 2008;371:569-78.

Cite this article as: Akalyaa K, Shakuntala PN, Renuka R. Correlation of body mass index and abnormal uterine bleeding in premenopausal women. Int J Reprod Contracept Obstet Gynecol 2020;9:4640-7. 